\title{
MeCANISMO DE FUNCIONAMIENTO DE LOS ADR (AMERICAN DEPOSITARY RECEIPTS) EN EL MERCADO FINANCIERO NORTEAMERICANO
}

\author{
Hernán Yacsahuache Pasapera \\ Docente de la Facultad de Ciencias Contables
}

\begin{abstract}
RESUMEN
A mediados del año 1993 surgió el interés de algunas empresas de gran envergadura en el país, inscritas en la Bolsa de Valores de Lima, por emitir ADR para acceder al mercado financiero norteamericano, motivando que el 21 de diciembre del año 1993, la CONASEV: publique la resolución 358-93-EF/ 94.10.0 normando la información que deben presentar las empresas que efectúen programas de ADR, la misma que recogió experiencias latinoamericanas. Esta reglamentación facilita que se internacionalice más el mercado peruano, que se de a conocer mucho más en el exterior; pero, dado el tiempo transcurrido, muy pocas son las empresas peruanas que han entrado en los programas de ADR. Es por ello el interés de divulgar este tema a los ejecutivos y funcionarios de las empresas del país como una fuente de financiamiento para sus proyectos de inversión y, desde luego, internacionalizar la empresa a través del mercado financiero norteamericano.

Es bueno mencionar, que el universo de empresas en nuestro país que podrían optar esta fuente de financiamiento es muy reducido, teniendo en cuenta que la capitalización mínima requerida de 100 millones de dólares apenas la ostentan alrededor de 15 empresas inscritas en la Bolsa de Valores.
\end{abstract}

Palabras clave: ADR: American Depositary Receipts.

\section{INTRODUCCIÓN}

Como consecuencia del reordenamiento tanto en el orden económico, político como social, los países de todo el orbe también han reorientado sus políticas, a fin de internacionalizar sus economías; entre los más destacables tenemos: los países latinoamericanos, Europa del este, parte de África, etc.

Lo antes mencionado sienta las bases para que estos países desarrollen sus economías, y dentro de ella está su mercado de capitales.
En lo que al Perú toca, se están dando las condiciones para el desarrollo y mantenimiento de un mercado de capitales atractivo.

Siendo los mercados internacionales de acciones una fuente importante de capital, han situado al Perú en una plaza atractiva para los inversionistas internacionales, entre los que destacan los inversionistas institucionales e individuales de Estados Unidos de América, quienes han evidenciado creciente interés en acciones extranjeras, en general, y en acciones 
latinoamericanas en particular, para lo cual han diseñado los ADR (American Depositary Receipts).

\section{DEFINICIÓN DE UN ADR}

Es un recibo de depósito otorgado por un banco norteamericano, que representa la titularidad de un número especificado de acciones no estadounidenses depositadas en el país de origen de la empresa.

En vista que los ADR constituyen prueba de titularidad de las acciones originales pueden ser negociados libremente en los Estados Unidos, sin la entrega de las acciones no estadounidenses que efectivamente representan.

\section{CARACTERÍSTICAS DE LOS ADR}

- Es un documento (instrumento) negociable.

- Permite tener certificados de acciones de empresas no norteamericanas.

- Se requiere la emisión de los $\mathrm{ADR}$ por parte de un banco depositario de los EE.UU.

- Las acciones de respaldo quedan en custodia en un banco local.

\section{III. ¿CÓMO OPERAN LOS ADR?}

\section{ADR NO PATROCINADOS}

Es una forma de emitir ADR, generalmente iniciado por uno o más corredores estadounidenses, debido al interés de los inversionistas en las acciones de una empresa no estadounidense. Los corredores solicitan a un banco depositario estadounidense que emita ADRs y se concede a la empresa no estadounidense una excepción de las disposiciones sobre información de la ley, Valores y Bolsa. Los bancos registran los ADR en la SEC, iniciándose así las operaciones.

Los bancos depositarios son compensados con las comisiones generadas por la emisión y cancelación de certificados y también descuentan comisiones de los pagos de dividendos antes de distribuirlos entre los titulares de ADR.

\section{ADR PATROCINADOS}

La diferencia es que un banco emisor decide promover activamente los ADR de la empresa en los EE.UU. Suele elegirse un solo banco depositario, y todos los futuros ADR son emitidos a través de este banco, que asume la función de responsable exclusivo del pago de dividendos, la distribución de información y la administración del programa.

En el caso de los ADR patrocinados, estos gastos corren por cuenta del banco depositario o emisor del ADR y no del titular de los ADR (inversionista).

\section{ADR NO REGISTRADOS}

Este procedimiento es elegido por las compañías que no desean registrarse en la SEC y presentar sus balances de conformidad a los USGAAP.

En cambio, proporcionan a la SEC una versión en inglés de su memoria anual.

\section{ADR REGISTRADOS}

Las compañías que están dispuestas a registrarse plenamente en la SEC, llenando información, que reconcilia sus cuentas con los USGAAP. Si satisfacen los requisitos de cotización establecidos, pueden solicitar ser cotizadas en cualquier bolsa norteamericana. 


\section{NIVELES DE EMISIÓN DE ADR}

Hay tres niveles de ADR a los que se puede acceder, los dos primeros son para acciones ya existentes en el mercado, y el tercero para la emisión de nuevas acciones

\section{ADR NIVEL I}

La emisión de ADR nivel I no requiere la presentación de información. Pueden ser negociados en el mercado OTC (over the counter), y permiten al inversionista extranjero invertir en acciones del mercado local vía $A D R$, nominados en dólares. Asimismo, brindan al emisor nacional la oportunidad de expandir y diversificar la base accionaria e incrementar el precio de su acción como resultado de una demanda y negociación global.

Este nivel de ADR, si bien no permite la emisión primaria de acciones, hace posible que el emisor adquiera imagen en el mercado financiero norteamericano, llegando a ser considerado como un primer paso hacia programas más avanzados.

\section{ADR NIVEL II}

Se negocian en la New Cork Stock Exchange (NYSE), la American Stock Exchange (AMEX) o la National Association of Securities Dealers Automated Quotation System (NASDAQ). A diferencia del nivel $I$, este nivel proporciona al inversionista una mayor y mejor información sobre el emisor, que está obligado a presentar información anual consolidada según el USGAAP que es el sistema contable estadounidense. Además da el acceso a un mercado más líquido.

Pero lo que no está permitido en este mecanismo es el aumento de capital.
De otro lado en los niveles de ADR I y II involucra la intervención del inversionista americano, un broker del mercado local (que es quien compra las acciones en la bolsa) y un banco custodio local (donde se depositan las acciones).

\section{ADR NIVEL III}

Los ADR de nivel III permiten la oferta primaria de ADR en los Estados Unidos y se encuentran inscritos en las mismas bolsas que los de nivel II.

Este nivel de ADR permite el acceso a una más amplia base de inversionistas, razón por la cual el emisor debe realizar una promoción muy amplia y activa a la comunidad de inversionistas (road show). Asimismo para acceder a este nivel de ADR se debe presentar los requerimientos de información a la SEC (USGAAP).

En los tres niveles de ADR se tiene que cumplir con la serie de requisitos de la SEC, que realiza una evaluación severa y rigurosa, además de lo que suceda una vez que la empresa está registrada en el mercado de valores de EE.UU.

\section{IMPORTANCIA DEL ADR EN PAÍSES EMERGENTES}

A causa del reordenamiento económico, político y social, los países de todo el orbe están reorientando sus políticas, a fin de internacionalizar sus economías y entre las más destacadas tenemos Europa del este, parte de África, Asia y los países latinoamericanos.

Estos países considerados como emergentes sientan las bases para desarrollar sus economías y dentro de ésta su mercado de capitales. 
En lo que se refiere específicamente a Perú se están dando ciertas condiciones para el desarrollo y mantenimiento de un mercado de capitales atractivo, en lo que se puede citar:

- Políticas económicas de libre mercado.

- Liberalización del mercado de cambios.

- Liberalización del régimen de comercio.

- Liberalización de la política de inversión extranjera.

- Estabilidad política a través de un congreso elegido democráticamente.

- Privatización de empresas en las que el Estado tiene participación.

- Crecimiento real del PBI de aproximadamente $5 \%$ con buenas proyecciones.

- Baja sensible del terrorismo.

Siendo los mercados internacionales de acciones una fuente importante de capital, han situado al Perú en una plaza atractiva para los inversionistas internacionales, entre los que destacan los inversionistas institucionales e individuales de Estados Unidos de América, quienes han evidenciado un creciente interés en acciones extranjeras, en general y en acciones latinoamericanas, en particular, para lo cual han diseñado los ADR (American Depositary Receipts).

\section{BENEFICIOS DEL ADR EN LA PERSPECTIVADEL INVERSIONISTA}

- Registrado en la SEC.

- Los inversionistas están familiarizados con el certificado de depósito (ADR), que satisface las normas estadounidenses.

- Fácil disponibilidad de información sobre la empresa y la cotización de sus ADRs

- Denominación en dólares.

- Los dividendos se pagan en dólares.

- Es menos costoso que la inversión directa.
VII. BENEFICIOS PARA UNA EMPRESA DEL PERÚ (NIVEL I)

- Amplía la base de accionistas de la empresa.

- Incrementa la visibilidad de la empresa del Perú en el mercado de capitales de EE.UU.

- Apoya, estabiliza y fortalece el precio de las acciones.

- Es un paso previo para futuras captaciones de capital en el mercado norteamericano.

\section{IMPLEMENTACIÓN DEL PROGRAMA ADR}

El tiempo de implementación del programa requiere de aproximadamente de 8 a 10 semanas.

PASOS A SEGUIR:

- Información a la SEC

- Formulación de registro con la SEC

- Convenio de depósito de los ADRs

- Anuncio en el mercado.

\section{EXPERIENCIA EXTRANJERA EN LA EMISIÓN DE ADR}

Las empresas del continente europeo son las que representan el mayor número de emisiones de ADR.

En el mercado europeo se concentra aproximadamente el $73 \%$ de los montos negociados y el $72 \%$ de acciones demandadas.

En segundo lugar se ubica Latinoamérica, con una participación del más del $20 \%$, tanto por los montos negociados como demandados.

Asia solo representa el 5\% del total.

En Latinoamérica, México concentra el $71 \%$ de los programas de ADR, siendo la 
empresa de teléfonos de México, la que se haya con la mayor emisión de ADRs, seguido por el grupo Televisa y la empresa Vitro. Las empresas mencionadas han emitido ADR en gran cantidad, en vista de los planes de expansión que tienen proyectados, como el grupo Televisa a nivel latinoamericano y la empresa Vitro, empresa productora de vidrio que ha penetrado el mercado estadounidense.

Venezuela se ubica en el segundo lugar en Latinoamérica, con una participación del $15.3 \%$, explicado por las emisiones de las empresas Corimon, Venepal y Veriprecar.

Argentina y Chile se ubican en el tercer y cuarto lugar, respectivamente, con participación del 6.8 y $3.4 \%$. En argentina, es la empresa Telecom la que tiene la mayor participación; en Chile, son las empresas de teléfonos de Chile, chilectra y compañía Cerveceras Unidas.

Los países de Brasil y El Salvador solo llegan a una emisión de apenas el 1.7\% del total para cada país.

\section{GLOSARIO DE TÉRMINOS}

- ADRs, American Depositary Receipts (Recibo de depósito Americano)

- Depositary Bank (banco depositario), banco extranjero que emite los ADRs
- USGAAP (Balances de conformidad con los principios contables, generalmente aceptados en los Estados Unidos)

- SEC, Securities and Exchange Comission (comisión de valores de los Estados Unidos de América). Institución donde se registran los $A D R s$ para su oferta pública y posterior negociación

- NYSE, New York Stock Exchange (bolsa de de valores de Nueva York)

- NASDAQ, National Association of Securities Dealers Automated Quotation (Bolsa de Valores de la Asociación Nacional de corredores de bolsa)

- AMEX, the American Stock Exchange (bolsa de valores en la ciudad de Nueva York), una de las bolsas nacionales

- OTC, over the Counter Market, Boletín

- IR, Investor Relation Firm (firma de relaciones con el inversionista), -se sobreentiende en USA-.

\section{REFERENCIAS}

SALLENAVE, J. P. Gerencia y Planeación Estratégica. Colombia, Edit. Norma, 1997.

WEBB, Richard. Una economia muy peruana.

WELLS, Louis T. The product life cycle and international Trade. Harvard University Press, 1974. 